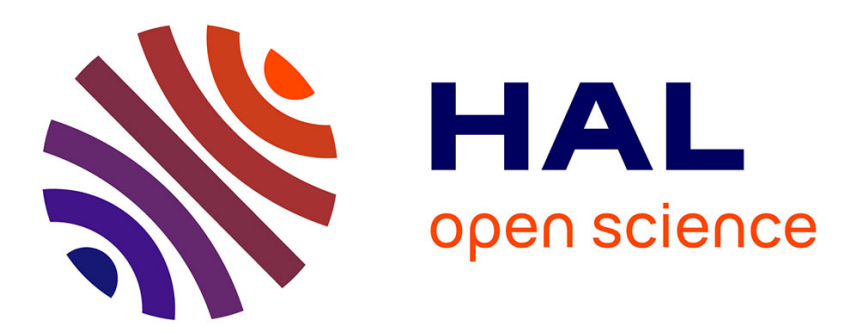

\title{
Adsorption Mechanisms of Psychoactive Drugs onto Montmorillonite
}

Thomas Thiebault, Mohammed Boussafir

\section{To cite this version:}

Thomas Thiebault, Mohammed Boussafir. Adsorption Mechanisms of Psychoactive Drugs onto Montmorillonite. Colloid and Interface Science Communications, 2019, 30, pp.100183. 10.1016/j.colcom.2019.100183 . insu-02110592

\section{HAL Id: insu-02110592 \\ https://hal-insu.archives-ouvertes.fr/insu-02110592}

Submitted on 29 Apr 2019

HAL is a multi-disciplinary open access archive for the deposit and dissemination of scientific research documents, whether they are published or not. The documents may come from teaching and research institutions in France or abroad, or from public or private research centers.
L'archive ouverte pluridisciplinaire HAL, est destinée au dépôt et à la diffusion de documents scientifiques de niveau recherche, publiés ou non, émanant des établissements d'enseignement et de recherche français ou étrangers, des laboratoires publics ou privés. 


\title{
Adsorption mechanisms of psychoactive drugs onto montmorillonite
}

\author{
Thomas Thiebault ${ }^{1,2 *}$, Mohammed Boussafir ${ }^{1}$
}

${ }^{1}$ ISTO, UMR 7327, CNRS, Université d'Orléans, BRGM, 1A Rue de la Férollerie, 45071 Orléans Cedex 2, France

${ }^{2}$ EPHE, PSL Research University, UMR 7619 METIS (SU, CNRS, EPHE), 4 place Jussieu, F-75005, Paris, France

thomas.thiebault@ephe.psl.eu

mohammed.boussafir@univ-orleans.fr

\section{February, 2019}

*To whom correspondence should be addressed. E-mail: thomas.thiebault@ephe.psl.eu. Phone: +33(0) 144275997

\begin{abstract}
The adsorption of psychoactive drugs (PADs) onto sodium-exchanged montmorillonite (NaMt) was investigated under two $\mathrm{pH}$ conditions. At $\mathrm{pH}=2.5$, the adsorption was performed through cation exchange and the three PADs were intercalated within the Na-Mt layers. However, the adsorption capacity was lower than the theoretical cation exchange capacity of Na-Mt due to the impact of the acidic conditions on the adsorbent. At $\mathrm{pH}=7.5$, only Codeine was protonated and its adsorption through cation exchange resulted in the highest amount adsorbed among the tested PADs. Diazepam was adsorbed through weak electrostatic interactions, whereas Oxazepam appeared to be intercalated within Na-Mt layers despite its neutral charge. Consequently, the variation in $\mathrm{pH}$ strongly impacts the affinity of PADs for NaMt. These initial results highlight the impact of raw clay on the fate of these contaminants within environmental compartments and could pave the way for a green solution to the removal of PADs from wastewater effluents.
\end{abstract}

Keywords: Psychoactive drugs; clay minerals; adsorption; cation exchange; intercalation 
Psychoactive Drugs (PADs) are among the most concentrated and frequently detected pharmaceutical products in numerous environmental compartments such as wastewaters [1], surface waters [2] and sedimentary archives [3], due to their incomplete removal in wastewater treatment plants (WWTPs) [4]. Their persistence within the environment raises serious issues due to their impact on the biota, such as for example their altering effect on the behavior of fish [5]. Therefore, it appears necessary to assess the potential of new solutions to improve the removal of PADs from WWTP effluents. Adsorption could be considered as an appropriate way for the removal of organic pollutants [6], if the selected adsorbent is low-cost and displays a high adsorption capacity and selectivity $[7,8]$. Raw clay minerals such as bentonites exhibit outstanding adsorption properties for some organic compounds, especially cationic ones [911]. However, the affinity of PADs with clay minerals has been poorly investigated, even though it could provide useful information about both the potential of a clay-based solution for the removal of PADs from WWTP effluents [12], and the fate of these compounds within environmental compartments [13]. Moreover, some clay minerals such as montmorillonite are also considered as biocompatible: they are used as active substances to cure enteritis or gastritis $[14,15]$, and are suggested to act as a carrier for the controlled release of active substances on therapeutic targets [16]. Investigating the adsorption mechanisms of PADs onto raw clay minerals by varying experimental conditions such as $\mathrm{pH}$ value would therefore make it possible to explore the potential of this type of adsorbent to represent an alternative solution for the removal of these contaminants and to control their fate within aquatic environments and/or their possible controlled release for medicinal purposes.

Hence, the aim of this study was to investigate (i) the potential of slightly modified smectite for the removal of three PADs, and (ii) the impact of a $\mathrm{pH}$ variation on adsorption mechanisms. To our knowledge, it is the first study to deal with such fundamental interaction mechanisms between PADs and clay minerals. 
The selected adsorbent was a Wyoming sodium smectite SWy-2 (Mt), obtained from the Source Clay Minerals Repository, University of Missouri (Columbia, MO). Its structural formula is $\left(\mathrm{Ca}_{0.12} \mathrm{Na}_{0.32} \mathrm{~K}_{0.05}\right)\left[\mathrm{Al}_{3.01} \mathrm{Fe}(\mathrm{III})_{0.41} \mathrm{Mn}_{0.01} \mathrm{Mg}_{0.54} \mathrm{Ti}_{0.02}\right]\left[\mathrm{Si}_{7,98} \mathrm{Al}_{0.02}\right] \mathrm{O}_{20}(\mathrm{OH})_{4}$. The Mt clay was fractionated to $<2 \mu \mathrm{m}$ by gravity sedimentation, purified and $\mathrm{Na}$ exchanged by well-established procedures [17]. The resulting Na exchanged Mt clay mineral (Na-Mt) shows a cation exchange capacity (CEC) of 80 meq per $100 \mathrm{~g}$ of clay [10,17]. The PADs, Codeine (COD), Diazepam (DIA) and Oxazepam (OXA), were purchased from Sigma-Aldrich Chemical, assuming a purity grade $>98 \%$ and were used without any further purification. The main properties and characteristics of the selected PADs are presented Table 1. Chemical reagents such as $\mathrm{HCl}$, $\mathrm{NaOH}$ were supplied by Sigma-Aldrich and used without further purification.

Table 1: Characteristics and properties of the selected PADs, with $\mathrm{M}$ the molecular weight in $\mathrm{g} \cdot \mathrm{mol}^{-1}$ and $\mathrm{Sol}_{\mathrm{w}}$ the solubility in water at $25^{\circ} \mathrm{C}$ in $\mathrm{mg} . \mathrm{L}^{-1}$, data from $[12,18]$

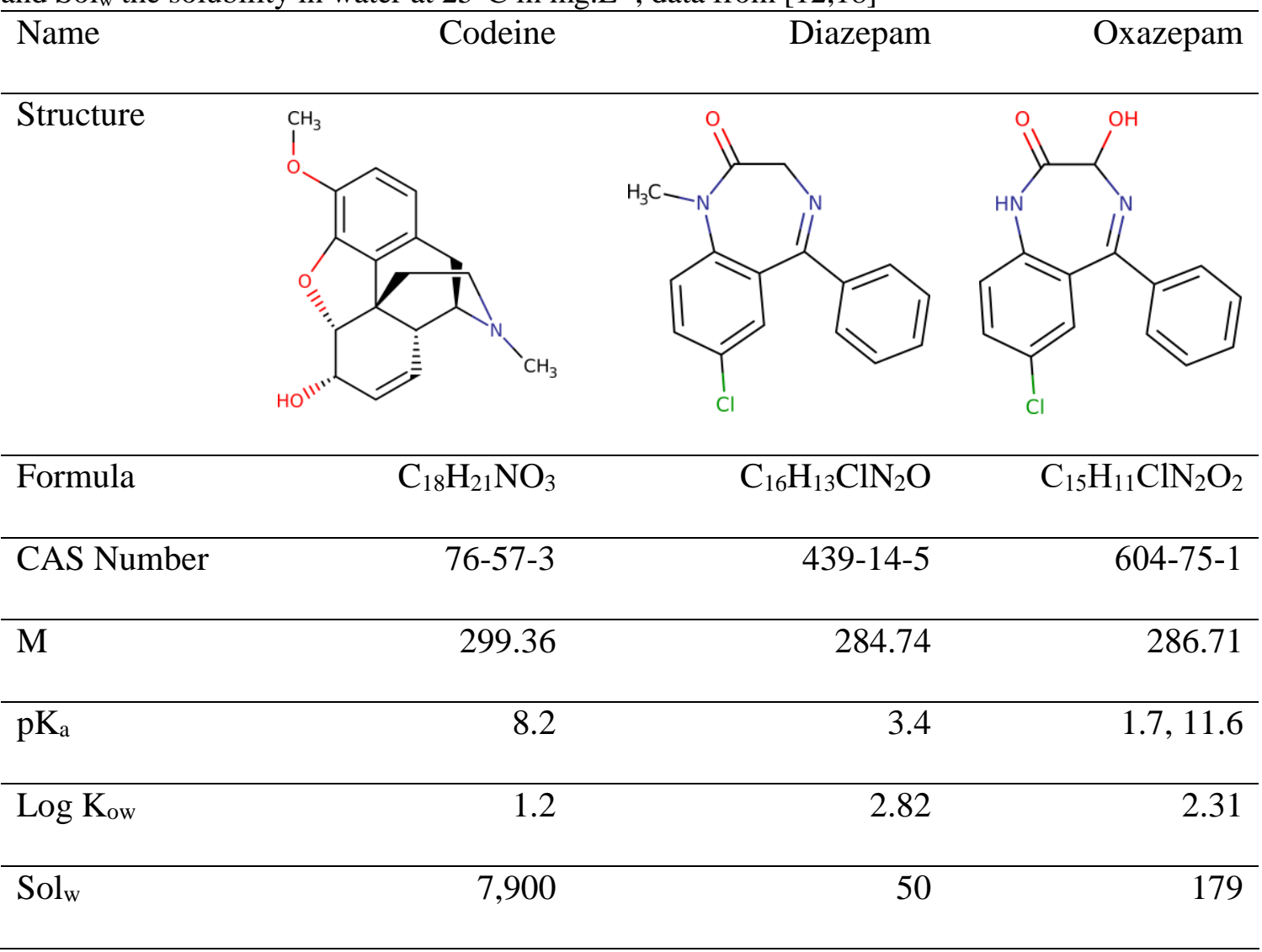

Batch sorption isotherms were conducted in duplicate using at least 9 initial aqueous concentrations ranging from $50 \mu \mathrm{g} . \mathrm{L}^{-1}$ to $50 \mathrm{mg} . \mathrm{L}^{-1}$. The prepared aqueous solutions of the 
PADs $(50 \mathrm{~mL})$ were added to $50 \mathrm{mg}$ of Na-Mt clay mineral sorbent in $50 \mathrm{~mL}$ centrifuge tubes. Two $\mathrm{pH}$ values were tested, $\mathrm{pH}=2.5$ and $\mathrm{pH}=7.5$, respectively. The $\mathrm{pH}$ values were adjusted by adding $\mathrm{HCl}$ and $\mathrm{NaOH}$. Samples were shaken on a rotary shaker at $250 \mathrm{rpm}$ for $16 \mathrm{~h}$ at room temperature in order to achieve the equilibrium of adsorption. The kinetics of the adsorption (not shown here) followed a similar trend for all three PADs [9]: the amount of PADs adsorbed increased as the initial concentration in solution increased while the values tended to be constant after a very short time, as previously observed for other organic compounds onto Na-Mt $[9,19]$. We therefore assumed that an equilibrium was reached after 150-300 min for all the selected PADs, allowing us to determine the adsorption isotherms which are fundamental for the description of the behavior between adsorbent and adsorbate. Both supernatant and adsorbent were separated by centrifugation (30 min, 8,000 rpm). The concentration of organic carbon in solution was measured using an elemental analyzer (Shimadzu TOC 5050 /SSM 5000-A) and the adsorbed amount was determined by elemental analysis (Carbon, Nitrogen) on dry $\left(100^{\circ} \mathrm{C}\right.$ during 24 hours) powdered samples using a Thermo Scientific Flash 2000 organic analyzer. Blank experiments were performed to control the carbon content of distilled water and Na-Mt. Before their characterization, the entire resulting layered composites (Mt-PADs) after adsorption of PADs were dried at $100^{\circ} \mathrm{C}$ for 24 hours to eliminate any hydration or adsorption of water of the samples. The $\mathrm{d}_{001}$ spacings of the starting Mt clay mineral and after being in contact with organic pollutants were determined by the first $00 l$ reflection from the X-ray patterns recorded in a conventional $\theta-\theta$ Bragg-Brentano configuration using a Thermo Electron ARL'XTRA diffractometer equipped with a $\mathrm{Cu}$ anode $\left(\mathrm{CuK}_{\alpha 1,2}=1.5418 \AA\right)$ coupled with a $\mathrm{Si}(\mathrm{Li})$ solid detector. The diffractograms on dry powdered samples were performed between 2 and $20^{\circ}(2 \theta)$ with an angular and time steps of $0.04^{\circ}$ and 10 s respectively. 


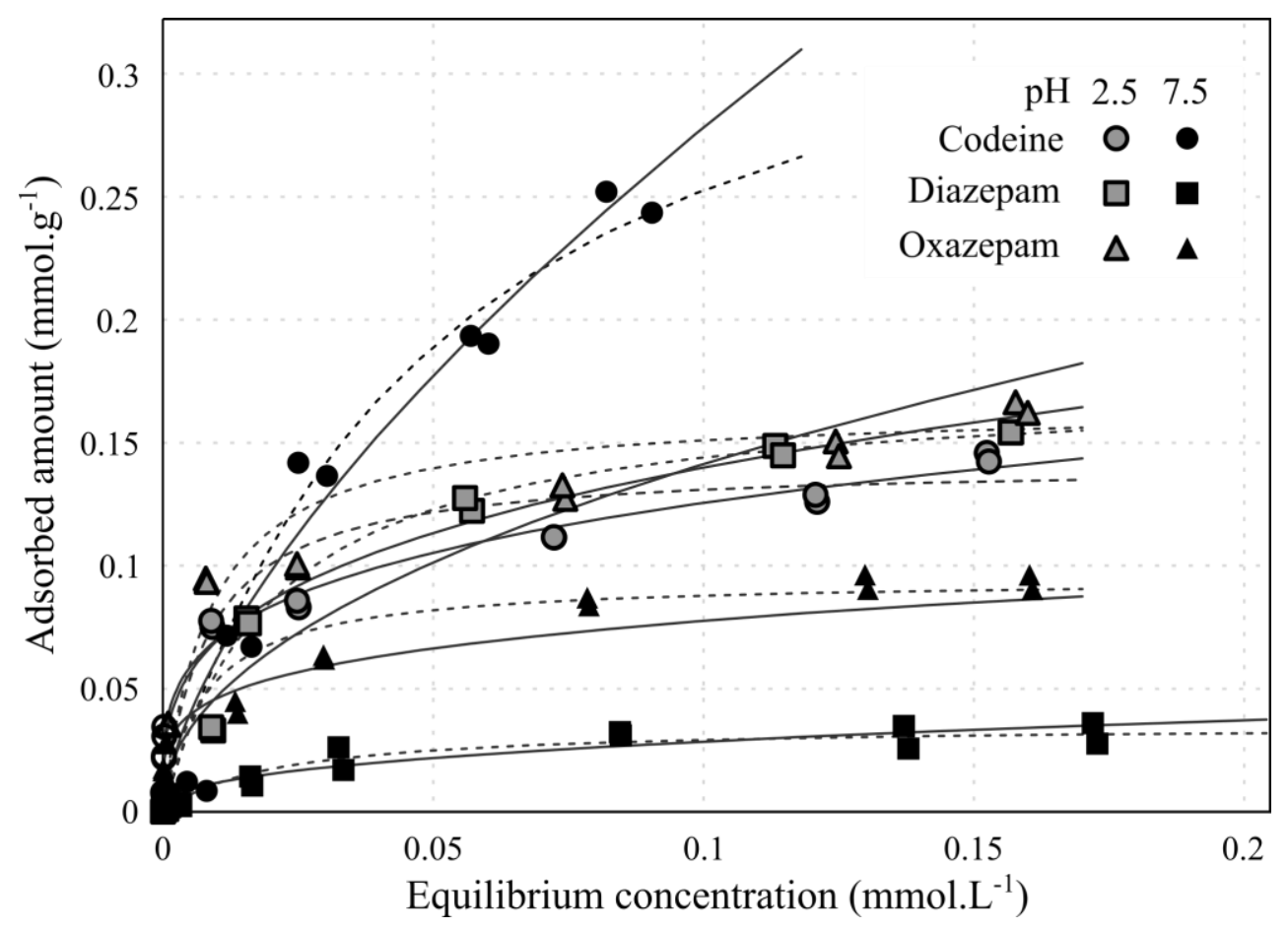

Figure 1: Adsorption isotherms of Codeine (circles), Diazepam (squares) and Oxazepam (triangles) onto Na-Mt at pH 2.5 (black symbols) and 7.5 (gray symbols), black lines represent the Freundlich fits, and dashed lines represent the Langmuir fits.

The adsorption isotherms of the three selected PADs onto the Na-Mt are presented in Figure 1. In the concentration range used in this work, a non-proportional evolution between equilibrium concentration and adsorbed concentration can be observed. The adsorption isotherms display two distinct regimes with the first indicating a gradual increase in the amount of PADs adsorbed with an equilibrium PAD concentration while the second displays a saturation level for the highest starting concentrations. Only the adsorption of $\mathrm{COD}$ at $\mathrm{pH}=7$ did not show any plateau, with a continuous increase of the adsorbed amount with the increase of the starting concentration. The impact of the variation in $\mathrm{pH}$ value on the adsorption of each PAD is different. Under acidic $\mathrm{pH}$ conditions (i.e. $\mathrm{pH}=2.5$ ) the adsorption capacity of COD is lower than at $\mathrm{pH}=7.5$, whereas the opposite pattern is observed for DIA and OXA (Figure 1). In general, the highest adsorption capacity is observed for COD at $\mathrm{pH}=7.5$ (i.e. $0.25 \mathrm{mmol} . \mathrm{g}^{-1}$ ) and the lowest adsorption capacity for DIA at $\mathrm{pH}=7.5$ (i.e. $0.036 \mathrm{mmol} . \mathrm{g}^{-1}$ ). 
Experimental data were fitted with three adsorption equations, Langmuir, Freundlich and Dubinin-Radushkevich (D-R), as the affinity of PADs with Na-Mt can be estimated with the model parameters. The Langmuir model is expressed by the following equation [10]:

$$
q_{e}=\frac{q_{\max } K_{L} C_{e}}{1+K_{L} C_{e}}
$$

where $q_{e}$ is the amount of PAD adsorbed onto Na-Mt $\left(m m o l . \mathrm{g}^{-1}\right), C_{e}$ the equilibrium PAD concentration in the supernatant $\left(\mathrm{mmol} . \mathrm{L}^{-1}\right), q_{\max }$ the maximum adsorption capacity of the sorbents $\left(\mathrm{mmol} . \mathrm{g}^{-1}\right)$ and $K_{L}$ the Langmuir adsorption constant $\left(\mathrm{L} . \mathrm{mmol}^{-1}\right)$ which is related to the free energy $\left(\Delta \mathrm{G}^{\circ}\right)$ of adsorption. The Freundlich equation can be expressed in its linear form as follows $[9,13]$ :

$$
\ln q_{e}=\ln K_{F}+\frac{1}{n} \ln C_{e}
$$

with $K_{F}$ the Freundlich affinity coefficient (in L.g ${ }^{-1}$ ), $n$ a linearity parameter and $C_{e}$ the equilibrium concentration in mol. $\mathrm{L}^{-1}$. The linear form of the D-R model is written as [8]:

$$
\ln q_{e}=\ln q_{m}+\beta \varepsilon^{2}
$$

with $q_{m}$ the calculated maximum adsorption capacity of the material in mol. $\mathrm{g}^{-1}, \beta$ a constant in $\mathrm{mol}^{2} . \mathrm{J}^{-2}$ and $\varepsilon$ the Polanyi potential expressed in $\mathrm{J}^{2} \cdot \mathrm{mol}^{-2}$ and calculated as follows [8]:

$$
\varepsilon=R T \ln \left(1+\frac{1}{C e}\right)
$$

with $R$ the gas constant in $\mathrm{J} \cdot \mathrm{mol}^{-1} \cdot \mathrm{K}^{-1}$ and $T$ the absolute temperature in $\mathrm{K}$.

$\beta$ is related to the mean free energy $E$ (in $\mathrm{kJ} \mathrm{mol}^{-1}$ ) by the following equation:

$$
E=(2 \beta)^{-1 / 2}
$$

The magnitude of $E$ gives information about whether the adsorption is chemisorption such as ion exchange $\left(8<E<16 \mathrm{~kJ} \cdot \mathrm{mol}^{-1}\right)$ or physical adsorption $\left(E<8 \mathrm{~kJ} \cdot \mathrm{mol}^{-1}\right)[8,20]$. 
Briefly, the Langmuir equation is based on the assumption of a monolayer adsorption onto a homogeneous adsorbent (i.e. adsorption sites display identical energy), whereas the Freundlich and D-R equations assume a heterogeneous adsorbent surface, and variability in the adsorption potential. Adsorption isotherms correctly fitted the experimental data with $\mathrm{r}^{2}$ values between 0.92 and 0.99 . The quality of the fit obtained meant that work could then be carried out on the resulting parameters (Table 2).

As previously mentioned, the only adsorption isotherm without any saturation level is at $\mathrm{pH}=$ 7.5 for COD (Figure 1). Under these $\mathrm{pH}$ conditions, COD is protonated (Figure S1) and could be adsorbed through cation exchange onto Mt [10,21]. This possible adsorption mechanism is emphasized by the $E$ value derived from the D-R model which is $>8 \mathrm{~kJ} \cdot \mathrm{mol}^{-1}$, indicative of chemisorption. In general, one of the most important limiting factors for the adsorption of cationic compounds onto clay minerals is the CEC, which is $0.8 \mathrm{mmol.g}^{-1}$ for Na-Mt [17]. In the concentration range used in this study, the highest adsorption capacity is $0.25 \mathrm{mmol} . \mathrm{g}^{-1}$ representing $~ 30 \%$ of the CEC of Na-Mt. The maximum adsorption capacities derived from Langmuir and DR model are 0.38 and $0.55 \mathrm{mmol} . \mathrm{g}^{-1}$, respectively, corresponding to 47 and 67 $\%$ of the CEC respectively (Table 2 ). At $\mathrm{pH}=7.5$, OXA and DIA are neutral (Figure S1) and their adsorption isotherms display a less favorable adsorption behavior than that of COD. Hence, the adsorption capacity is lower (i.e. 0.035 and $0.095 \mathrm{mmol} . \mathrm{g}^{-1}$ for DIA and OXA according to Langmuir equation parameters, respectively) and the saturation level is quickly attained. This result highlights the quick saturation of the adsorption sites of Na-Mt for these neutral compounds. At this $\mathrm{pH}$, the three models properly fitted the experimental data (Table 2).

However, under acidic $\mathrm{pH}$ conditions (i.e. $\mathrm{pH}=2.5$ ) the Langmuir equation fits the experimental data better than the Freundlich equation. Indeed, this latter equation does not reflect any saturation level. Based on the assumptions of the Langmuir equation, this indicates 
that the adsorption is limited to a monolayer with equal adsorption energy for each adsorption site. Therefore, under these $\mathrm{pH}$ conditions, $\mathrm{COD}$ and DIA are both protonated and OXA is only partially protonated ( $20 \%$, Figure $\mathrm{S} 1)$. The adsorption capacity of each PAD is similar at $\mathrm{pH}$ $=2.5$, indicating that the acidification of the solution impacts the behavior of both the adsorbates and the adsorbent. Acidification is favorable for the adsorption of OXA and DIA whereas it can be considered as unfavorable for the adsorption of COD. The adsorbed amount of the three PADs reaches an equilibrium between 0.14 and 0.17 mmol. $\mathrm{g}^{-1}$ according to Langmuir equation which represents $\sim 20 \%$ of the CEC of Na-Mt. The $E$ values, derived from the D-R equation, are systematically higher than $8 \mathrm{~kJ} \cdot \mathrm{mol}^{-1}$, indicating chemisorption (Table 2).

Table 2. Equilibrium adsorption isotherm constants determined with the Langmuir, Freundlich, and Dubinin-Radushkevich model fits for the adsorption of Diazepam, Oxazepam, and Codeine onto an Naexchanged smectite clay mineral.

\begin{tabular}{|c|c|c|c|c|c|c|c|c|c|c|c|}
\hline \multirow[t]{2}{*}{ PP } & \multirow[t]{2}{*}{$\mathrm{pH}$} & \multicolumn{4}{|l|}{ Langmuir } & \multicolumn{3}{|c|}{ Freundlich } & \multicolumn{3}{|c|}{ Dubinin-Radushkevich (D-R) } \\
\hline & & $\begin{array}{c}\mathrm{q}_{\max } \\
\left(\mathrm{mmol} . \mathrm{g}^{-}\right. \\
1)\end{array}$ & $\begin{array}{c}\mathrm{K}_{\mathrm{L}} \\
\left(\mathrm{L} . \mathrm{mmol}^{-}\right. \\
1)\end{array}$ & $\begin{array}{c}\Delta \mathrm{G}^{\circ} \\
\left(\mathrm{kJ} \cdot \mathrm{mol}^{-}\right. \\
1)\end{array}$ & $\mathrm{r}^{2}$ & $\mathrm{n}$ & $\begin{array}{l}\mathrm{K}_{\mathrm{F}} \\
\left(\mathrm{L} . \mathrm{g}^{-}\right. \\
1)\end{array}$ & $r^{2}$ & $\underset{\substack{\mathrm{q}_{\mathrm{m}} \\
1 \\
\mathrm{mmol} . \mathrm{g}^{-}}}{ }$ & $\begin{array}{c}\mathrm{E} \\
\left(\mathrm{kJ} \cdot \mathrm{mol}^{-}\right. \\
1)\end{array}$ & $\mathrm{r}^{2}$ \\
\hline \multirow{2}{*}{ Codeine } & 2.5 & 0.141 & 123.85 & -11.75 & 0.981 & 3.95 & 0.22 & 0.973 & 0.137 & 11.18 & 0,964 \\
\hline & 7.5 & 0.381 & 19.68 & -7.26 & 0.950 & 1.54 & 1.24 & 0.930 & 0.553 & 9.33 & 0,949 \\
\hline \multirow{2}{*}{ Diazepam } & 2.5 & 0.174 & 48.53 & -9.46 & 0.999 & 2.08 & 0.43 & 0.965 & 0.260 & 10.43 & 0,975 \\
\hline & 7.5 & 0.035 & 48.80 & -9.48 & 0.923 & 2.61 & 0.07 & 0.929 & 0.035 & 6.32 & 0,915 \\
\hline \multirow{2}{*}{ Oxazepam } & 2.5 & 0.164 & 114.73 & -11.56 & 0.988 & 3.30 & 0.28 & 0.878 & 0.209 & 11.11 & 0,937 \\
\hline & 7.5 & 0.095 & 129.82 & -11.86 & 0.957 & 4.43 & 0.13 & 0.946 & 0.077 & 8.16 & 0,903 \\
\hline
\end{tabular}

The modification of the $\mathrm{pH}$ value also impacts the adsorbent. Na-Mt presents two types of charge, with (i) the permanent negative charges generated by the isomorphic substitutions in the layer (e.g. $\mathrm{Al}-\mathrm{Fe}$ ) and (ii) the amphoteric charges on the edge-sites of clay minerals [22]. The variation in the $\mathrm{pH}$ conditions reinforces the charge on the edge-sites of Na-Mt. With a $\mathrm{pH}_{\mathrm{znpc}}$ (zero net proton charge) around 6.5 [23], the edge-sites of Na-Mt are protonated for $\mathrm{pH}$ $<\mathrm{pH}_{\mathrm{znpc}}$ whereas they are deprotonated at $\mathrm{pH}>\mathrm{pH}_{\mathrm{znpc}}$. That is why acidification of the solution avoids the participation of edge-sites in the CEC of the whole clay minerals. Moreover, acidification of the solution also destabilizes the clay mineral [24], and increases the concentration of $\mathrm{H}^{+}$in the solution. However, $\mathrm{H}^{+}$in excess could be preferentially adsorbed in 
comparison to other cations such as PADs [23]. According to the results, the CEC of Na-Mt seems to be considerably reduced at $\mathrm{pH}=2.5$, with an approximate value of $0.15 \mathrm{mmol} . \mathrm{g}^{-1}$, representing $20 \%$ of the $\mathrm{CEC}$ at $\mathrm{pH}=7.5$ (Figure 1 ).

In order to highlight the sorption mechanisms of PADs onto clays, XRD analyses were conducted to investigate possible shifts in the basal spacing of the adsorbents (derived from $\mathrm{d}_{001}$ angular values) accompanying an increase in the amount of PAD adsorbed. The diffractograms of adsorbent after interaction at $\mathrm{pH}=7.5$ are presented in Figure 2. The basal spacings of NaMt after interaction with DIA did not show any shift, whatever the starting concentration of DIA. Conversely, the basal spacing of Na-Mt after interaction with both COD and OXA increased for the highest starting concentrations, from $10.4 \AA$ to 14.5 and $13.3 \AA$ for COD and OXA respectively. As a result, it can be assumed that an intercalation occurs for COD and OXA within the Na-Mt layers, whereas DIA is only adsorbed on the external surface at $\mathrm{pH}=7.5$.

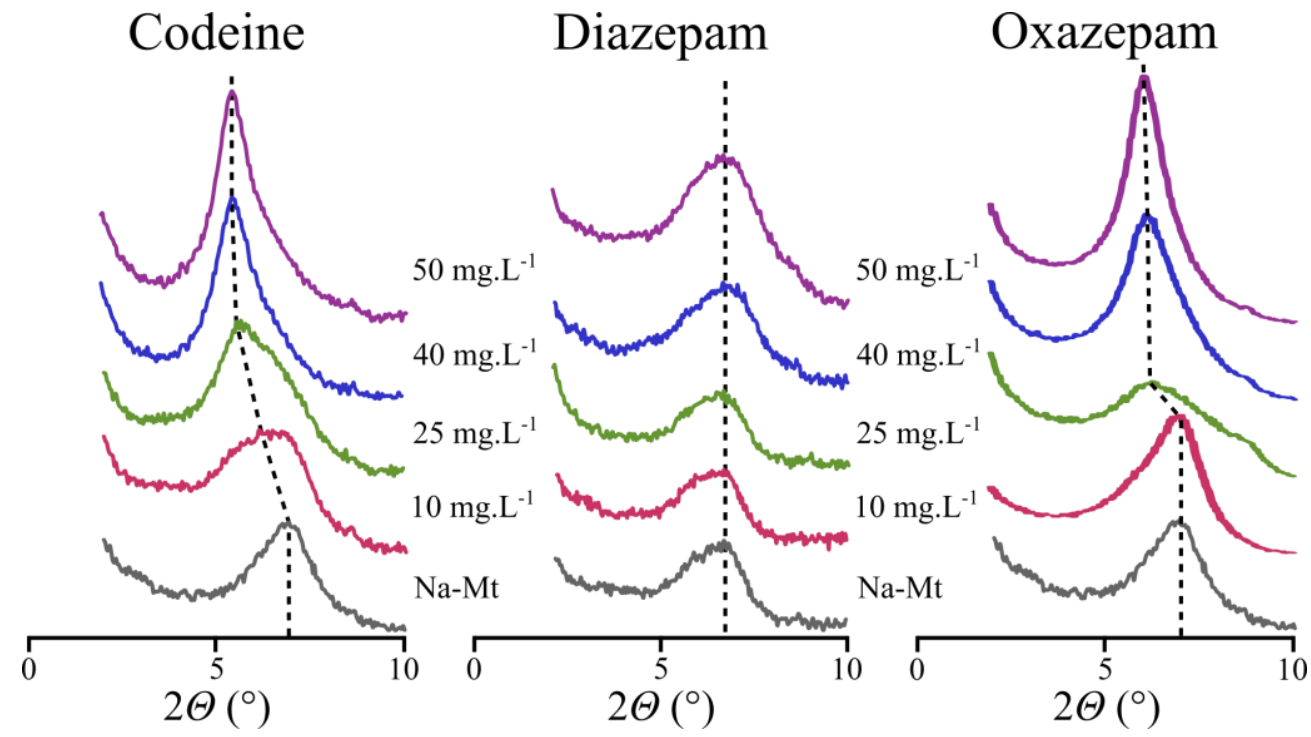

Figure 2: X-Ray diffraction patterns of a PAD-Na-Mt layered composite as a function of the starting PAD concentration at $\mathrm{pH}=7.5$

Under acidic $\mathrm{pH}$ conditions $(\mathrm{pH}=2.5)$ the basal spacing of $\mathrm{Na}-\mathrm{Mt}$ after interaction with the PADs displays a gradual increase (Figure 3) from $10.4 \AA$ to $12.2,12.5$ and $13.6 \AA$ after 
interaction with the highest starting concentration of DIA, OXA and COD respectively (Figure 3). All the PADs are intercalated within the layers of $\mathrm{Na}-\mathrm{Mt}$ at this $\mathrm{pH}$ value.

However, the increase in the basal spacing is lower at $\mathrm{pH}=2.5$ than at $\mathrm{pH}=7.5$ (except for DIA-NaMt, for which no increase in basal spacing is observed at $\mathrm{pH}=7.5$ ). This agrees with the lower adsorption capacity of $\mathrm{COD}$ at $\mathrm{pH}=2.5$ in comparison with $\mathrm{pH}=7.5$. Conversely, the increase in the basal spacing for OXA is higher at $\mathrm{pH}=7.5$, although the adsorption capacity is higher at $\mathrm{pH}=2.5$. This indicates that the impact of the $\mathrm{pH}$ modification on the adsorbent impacts the conformation of the resulting PAD-Na-Mt composite after adsorption.

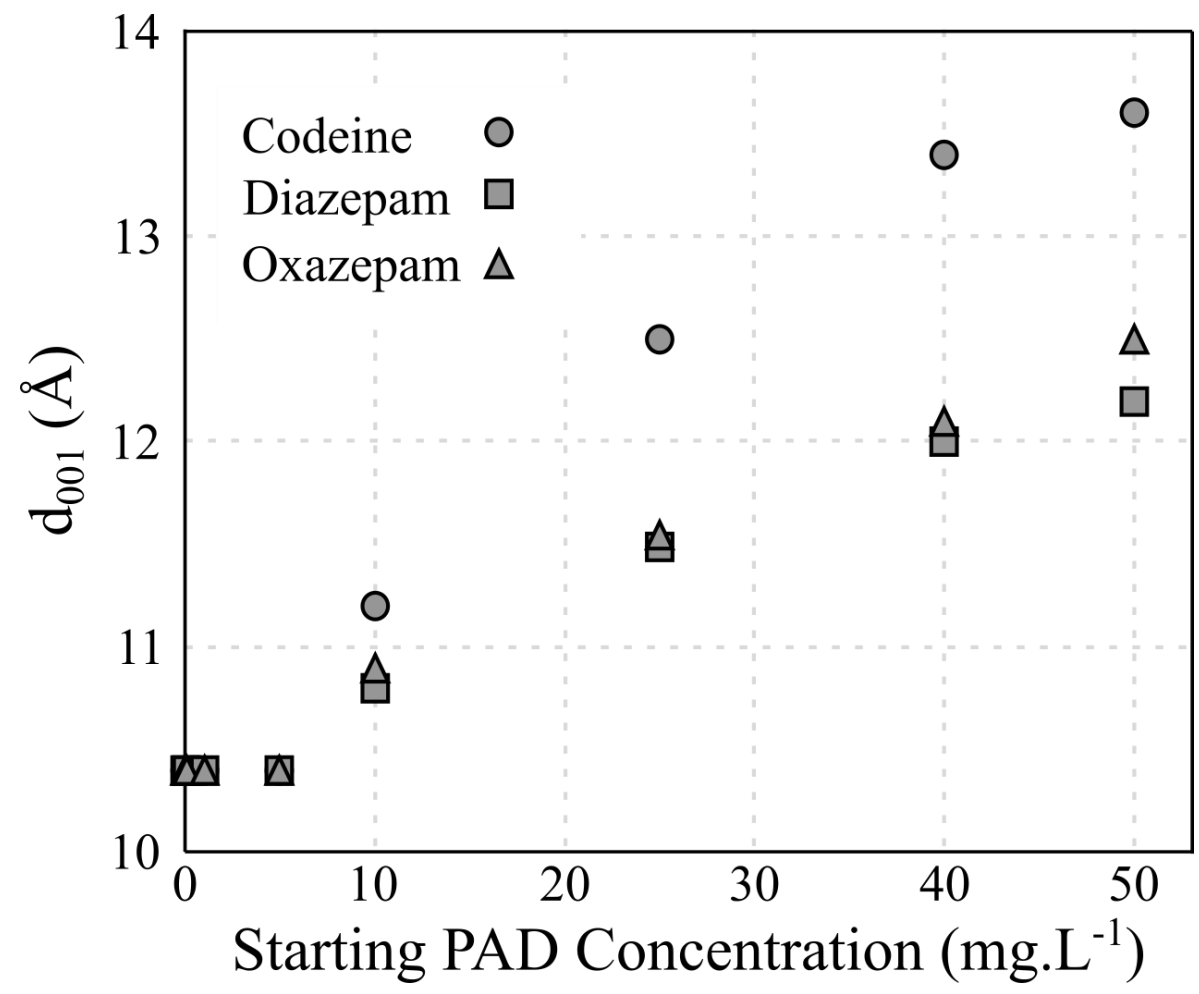

Figure 3: Evolution of the $\mathrm{d}_{001}$ basal spacing determined by the $00 l$ reflection obtained from X-Ray Diffraction patterns of PAD-Na-Mt composites as a function of the starting PAD concentration at $\mathrm{pH}=$ 2.5

Therefore, in the tested conditions, the adsorption of COD is realized through cation exchange whatever the $\mathrm{pH}$ conditions. $\mathrm{COD}$ is in cationic form in the two $\mathrm{pH}$ conditions tested, and its favorable adsorption behavior is attested by the $E$ values (i.e. $\left.>8 \mathrm{~kJ} \cdot \mathrm{mol}^{-1}\right)$ and by the good fits with the Langmuir equation due to $\mathrm{Na}^{+}$cation exchange mechanisms. Conversely, DIA is 
adsorbed through weak electrostatic interactions at $\mathrm{pH}=7.5$ due to its neutral charge [25], according to the unfavorable adsorption behavior and the lack of shift in the $\mathrm{d}_{001}$ values (Figure 2). However, at $\mathrm{pH}=2.5$, since $\mathrm{pH}<\mathrm{pKa}$, DIA is adsorbed through cation exchange and is intercalated within Na-Mt layers [26]. For OXA, the adsorption mechanism seems to be more tricky. According to its theoretical speciation, OXA should be neutral at $\mathrm{pH}=7.5$ (Figure $\mathrm{S} 1$ ); however, an intercalation is observed (Figure 2). Moreover, the adsorption isotherms were wellfitted by the Langmuir equation in this $\mathrm{pH}$ condition and the $E$ value was $>8 \mathrm{~kJ}^{\mathrm{mol}}{ }^{-1}$ (Table 2). As a result, it is possible that a significant proportion of OXA is protonated under these $\mathrm{pH}$ conditions, contrary to chemical database information, or more probably that neutral OXA was intercalated through ion-dipole interaction or some other mechanism [27]. At $\mathrm{pH}=2.5$, a significant part of OXA is protonated, resulting in the possible intercalation within Na-Mt layers through cation exchange.

It should be mentioned here that acidification of the solution modifies the conformation of PADs intercalated within Na-Mt. Hence, at $\mathrm{pH}=2.5$, the increase in the basal spacing is lower than at $\mathrm{pH}=7.5$, probably due to the adsorption as a monolayer in acidic conditions whereas another conformation (e.g. bilayer) may be assumed at $\mathrm{pH}=7.5$. Moreover, the greater increase in the basal spacing of PAD-Na-Mt composites after adsorption of COD in comparison with DIA and OXA can be explained by the larger size of the COD molecules (Table 1).

In this work, it has been shown that the extent to which PADs are adsorbed onto Na-Mt is mainly controlled by the $\mathrm{pH}$ value. Acidification of the solution modifies both the adsorption mechanisms of DIA and OXA and also impacts the adsorption capacity of the adsorbent. Hence, cation exchange is the main adsorption mechanism under acidic conditions whereas weak electrostatic interactions can be significant at $\mathrm{pH}=7.5$ depending on the $\mathrm{pK}_{\mathrm{a}}$ of the PADs. From this work, it appears that clay minerals could represent a green solution for the removal of PADs 
from wastewater effluents and can constitute a key natural material controlling the fate of these contaminants within environmental compartments.

\section{Acknowledgments}

The work received financial support from the HArPE Project (2012-00073536) funded by the

Région Centre Val de Loire. The authors would also like to thank Marielle Hatton for carbon elemental analysis.

\section{References}

[1] T. Thiebault, L. Fougère, E. Destandau, M. Réty, J. Jacob, Temporal dynamics of humanexcreted pollutants in wastewater treatment plant influents: Toward a better knowledge of mass load fluctuations, Sci. Total Environ. 596-597 (2017) 246-255. doi:10.1016/j.scitotenv.2017.04.130.

[2] V. Calisto, V.I. Esteves, Psychiatric pharmaceuticals in the environment, Chemosphere. 77 (2009) 1257-1274. doi:10.1016/j.chemosphere.2009.09.021.

[3] T. Thiebault, L. Chassiot, L. Fougère, E. Destandau, A. Simonneau, P. Van Beek, M. Souhaut, E. Chapron, Record of pharmaceutical products in river sediments: A powerful tool to assess the environmental impact of urban management?, Anthropocene. 18 (2017) 47-56. doi:10.1016/j.ancene.2017.05.006.

[4] T. Thiebault, M. Boussafir, C. Le Milbeau, Occurrence and removal efficiency of pharmaceuticals in an urban wastewater treatment plant: mass balance, fate and consumption assessment, J. Environ. Chem. Eng. 5 (2017) 2894-2902. doi:doi:10.1016/j.jece.2017.05.039.

[5] T. Brodin, S. Piovano, J. Fick, J. Klaminder, M. Heynen, M. Jonsson, Ecological effects of pharmaceuticals in aquatic systems - impacts through behavioural alterations, Philos. Trans. R. Soc. Lond. B Biol. Sci. 369 (2014) 20130580. doi:10.1098/rstb.2013.0580.

[6] I. Ali, M. Asim, T.A. Khan, Low cost adsorbents for the removal of organic pollutants from wastewater, J. Environ. Manage. $113 \quad$ (2012) 170-183. doi:10.1016/j.jenvman.2012.08.028.

[7] A. Gil, L. Santamaría, S.A. Korili, Removal of caffeine and diclofenac from aqueous solution by adsorption on multiwalled carbon nanotubes, Colloid Interface Sci. Commun. 22 (2018) 25-28. doi:10.1016/j.colcom.2017.11.007.

[8] T. De Oliveira, R. Guégan, T. Thiebault, C.L. Milbeau, F. Muller, V. Teixeira, M. Giovanela, M. Boussafir, Adsorption of diclofenac onto organoclays: Effects of surfactant and environmental ( $\mathrm{pH}$ and temperature) conditions, J. Hazard. Mater. 323, Part A (2017) 558-566. doi:10.1016/j.jhazmat.2016.05.001.

[9] T. Thiebault, M. Boussafir, L. Le Forestier, C. Le Milbeau, L. Monnin, R. Guegan, Competitive adsorption of a pool of pharmaceuticals onto a raw clay mineral, RSC Adv. 6 (2016) 65257-65265. doi:10.1039/C6RA10655B.

[10] T. Thiebault, R. Guégan, M. Boussafir, Adsorption mechanisms of emerging micropollutants with a clay mineral: Case of tramadol and doxepine pharmaceutical products, J. Colloid Interface Sci. 453 (2015) 1-8. doi:10.1016/j.jcis.2015.04.029. 
[11] J.-F. Lambert, 7 - Organic pollutant adsorption on clay minerals, in: R. Schoonheydt, C.T. Johnston, F. Bergaya (Eds.), Dev. Clay Sci., Elsevier, 2018: pp. 195-253. doi:10.1016/B978-0-08-102432-4.00007-X.

[12] T. Thiebault, M. Boussafir, R. Guégan, C. Le Milbeau, L. Le Forestier, Clayey-sand filter for the removal of pharmaceuticals from wastewater effluent: percolation experiments, Environ. Sci. Water Res. Technol. 2 (2016) 529-538. doi:10.1039/C6EW00034G.

[13] K. Stein, M. Ramil, G. Fink, M. Sander, T.A. Ternes, Analysis and sorption of psychoactive drugs onto sediment, Environ. Sci. Technol. 42 (2008) 6415-6423. doi:10.1021/es702959a.

[14] M. Ghadiri, W. Chrzanowski, R. Rohanizadeh, Biomedical applications of cationic clay minerals, RSC Adv. 5 (2015) 29467-29481. doi:10.1039/C4RA16945J.

[15] M.I. Carretero, Clay minerals and their beneficial effects upon human health. A review, Appl. Clay Sci. 21 (2002) 155-163. doi:10.1016/S0169-1317(01)00085-0.

[16] E. Ruiz-Hitzky, P. Aranda, M. Darder, G. Rytwo, Hybrid materials based on clays for environmental and biomedical applications, J. Mater. Chem. 20 (2010) 9306-9321. doi:10.1039/C0JM00432D.

[17] L. Le Forestier, F. Muller, F. Villieras, M. Pelletier, Textural and hydration properties of a synthetic montmorillonite compared with a natural Na-exchanged clay analogue, Appl. Clay Sci. 48 (2010) 18-25. doi:10.1016/j.clay.2009.11.038.

[18] DrugBank,. http://www.drugbank.ca/ (accessed February 1, 2019).

[19] P.-H. Chang, W.-T. Jiang, Z. Li, C.-Y. Kuo, J.-S. Jean, W.-R. Chen, G. Lv, Mechanism of amitriptyline adsorption on Ca-montmorillonite (SAz-2), J. Hazard. Mater. 277 (2014) 44-52. doi:10.1016/j.jhazmat.2013.12.004.

[20] A. Sdiri, T. Higashi, T. Hatta, F. Jamoussi, N. Tase, Evaluating the adsorptive capacity of montmorillonitic and calcareous clays on the removal of several heavy metals in aqueous systems, Chem. Eng. J. 172 (2011) 37-46. doi:10.1016/j.cej.2011.05.015.

[21] L. Aristilde, B. Lanson, J. Miéhé-Brendlé, C. Marichal, L. Charlet, Enhanced interlayer trapping of a tetracycline antibiotic within montmorillonite layers in the presence of $\mathrm{Ca}$ and Mg, J. Colloid Interface Sci. 464 (2016) 153-159. doi:10.1016/j.jcis.2015.11.027.

[22] E. Tombácz, M. Szekeres, Surface charge heterogeneity of kaolinite in aqueous suspension in comparison with montmorillonite, Appl. Clay Sci. 34 (2006) 105-124. doi:10.1016/j.clay.2006.05.009.

[23] E. Tombácz, M. Szekeres, Colloidal behavior of aqueous montmorillonite suspensions: the specific role of $\mathrm{pH}$ in the presence of indifferent electrolytes, Appl. Clay Sci. 27 (2004) 75-94. doi:10.1016/j.clay.2004.01.001.

[24] M. Gautier, F. Muller, J.-M. Beny, L.L. Forestier, P. Alberic, P. Baillif, Interactions of ammonium smectite with low-molecular-weight carboxylic acids, Clay Miner. 44 (2009) 207-219. doi:10.1180/claymin.2009.044.2.207.

[25] W. Zhang, Y. Ding, S.A. Boyd, B.J. Teppen, H. Li, Sorption and desorption of carbamazepine from water by smectite clays, Chemosphere. 81 (2010) 954-960. doi:10.1016/j.chemosphere.2010.07.053.

[26] M.E. Parolo, M.C. Savini, J.M. Vallés, M.T. Baschini, M.J. Avena, Tetracycline adsorption on montmorillonite: $\mathrm{pH}$ and ionic strength effects, Appl. Clay Sci. 40 (2008) 179-186. doi:10.1016/j.clay.2007.08.003.

[27] R. Guégan, E. Veron, L. Le Forestier, M. Ogawa, S. Cadars, Structure and dynamics of nonionic surfactant aggregates in layered materials, Langmuir. 33 (2017) 9759-9771. doi:10.1021/acs.langmuir.7b01831. 